\title{
A Review of Behavioral Decision Making in the Newsvendor Problem
}

\author{
Abhishek Sharma \\ Indian Institute of Management Rohtak, Haryana, India \\ Email: aabhisheksharma01@gmail.com (Corresponding author) \\ Shirsendu Nandi \\ Indian Institute of Management Rohtak, Haryana, India \\ Email: shir.05math@gmail.com
}

\begin{abstract}
Schweitzer and Cachon (2000) demonstrated that choices of decision-maker in the newsvendor problem setting systematically deviate from those that maximize their expected profit. Since then, a large body of empirical and theoretical studies has been published to describe the newsvendor decisionmaking behavior. To establish further, the purpose of this paper is twofold. First, it identifies the various behavioral theories and biases that explain the newsvendor behavior by employing a systematic literature review of peer-reviewed articles published in leading journals from 2000 to 2017. Second, it classifies and analyzes the identified literature from three dimensions of human behavior namely: individual decision making biases, social preferences, and cultural aspects. Our findings from the review show that research has primarily emphasized individual decision making biases while social and cultural aspects lack analysis and are worthy of investigation. Finally, we discuss some directions for future research, followed by the conclusion and limitations of this review.
\end{abstract}

Keywords: behavioral operations management, newsvendor problem, literature review

\section{INTRODUCTION AND MOTIVATION}

The newsvendor problem has a rich history in the literature of inventory management (Silver et al. 1998, Porteus 2002). It serves as the basis for developing mathematical models in inventory problems to determine optimal order quantities. In the classical newsvendor problem, a manager has to decide on how much order quantity to stock in advance for the upcoming selling season. Here, the product is perishable, and the customer demand is stochastic in nature. He gets only one-time opportunity to place the order, and further replenishments are not possible. Therefore, if the order placed is greater than the realized demand, he must dispose the leftover stock at a loss (overage cost). And, if the order placed is lower than the realized demand, then he loses sales (underage cost). As a result, he has to decide the appropriate order quantity, to balance between the costs of overage and underage.

The traditional newsvendor model has relied on the assumptions of neoclassical economic approach which is based on the belief that humans have rational preferences and are capable of making the decisions that maximize their utility or profit. But, this is unreasonable in reality (Simon 1955). It does mean that the decision maker will place those order quantities that maximize his expected-profit. However, despite the fact that optimal order in a newsvendor problem can theoretically be calculated easily, there has been significant evidence from many controlled human experiments and surveys that the manager's inventory decisions do not always correspond to the optimal order quantity (Carlson and O'keefe 1969, Sterman 1989, Diehl and Sterman 1995, Fisherman and Raman 1996).

To the best of our knowledge, one of the earliest work to study decision biases in the newsvendor problem context is Schweitzer and Cachon (2000), who conducted two controlled laboratory experiments over Duke University MBA students, to investigate the inventory decisions and attempted to disentangle biases. They played 30-rounds of game and the participants were solicited with the information about the realized demand, profit and the aggregate profit at the end of each period. The results showed that the 'average' choice responses of participants tend to systematically deviate from optimal solutions. They found that the average order quantities in their experimental data, amounts below the optimal level when profit-margin is relatively high, and above the optimal level when profit-margin is relatively low. In both these regimes of high profit-margin and low-profit margins, the average choices were converged towards the mean demand. This phenomenon is called "pull-to-center" (PTC hereafter) effect. Later on, several other studies also confirmed the similar too low/too high pattern (else, underordering and over-ordering) of choices in newsvendor experiment (Benzion et al. 2008, Bolton and Katok 2008, Bostian et al. 2008, Lurie and Swaminathan 2009, Kremer et al. 2010, Moritz et al. 2013). These studies provide insights into identifying biases and decision heuristics of individual decision making in newsvendor setting.

Apart from the study of individual behavior perspective, Wu and Neiderhoff (2014) explained the impact of social preferences on the choices of selling to a newsvendor. Feng et al. (2011), Cui et al. (2013) demonstrated the cultural aspect as the influencing factor of behavior in these settings. The recent reviews on behavioral operations suggest how to incorporate more realistic behavioral attributes in a variety of operations management 
models (Bendoly et al. 2006, Loch and Wu 2007, Gino and Pisano 2008, Bendoly et al. 2010). This emerging literature draws its references from experimental and behavioral economics, judgment and decision making from psychology, organizational behavior and decision analysis from management (Gans and Croson 2008). Specifically, Loch and $\mathrm{Wu}$ (2007) examine behavioral issues due to three dimensions of human behavior namely: individual decisionmaking biases, social preferences, and cultural aspects.

The purpose of our paper is to summarize and synthesize the articles published after Schweitzer and Cachon (2000), and which incorporate behavioral issues in the context of newsvendor problem. We have adopted the approach of Loch and $\mathrm{Wu}$ (2007) to classify and analyze the identified literature from three dimensions of human behavior (as mentioned above). In contrast to the previous reviews on newsvendor problem, this paper focuses on behavioral theories and biases that impact in managing inventory decisions. Noting that little research has addressed this topic, the comprehensive review provided here aims to offer a new theoretical understanding of individual's cognizance while taking inventory decisions. The paper presents future research directions and implications for scholars to enhance their contributions in the field further. As newsvendor problem applies in a broad array of settings within operations management, knowledge pertaining to human behavior will also be useful for practitioners to mitigate the sub-optimal decisions by understanding the psychology behind decision making and hence benefit their organization.

To this end, this paper is structured as follows. We begin with a brief description of classical newsvendor problem in section 2 . In section 3 , we describe the research methodology followed in this paper. Next, we provide analysis of the papers in section 4 . In section 5, we discuss the future research directions. Finally, conclusions are presented, along with limitations of this paper in section 6 .

\section{THE CLASSICAL NEWSVENDOR PROBLEM}

Since the early 20th century, the Newsvendor problem has been extensively studied in the literature of inventory management to find the optimal stocking quantity under uncertain demand condition (Whitin 1955, Mills 1959, Karlin and Carr 1962). Many reviews and extensions to the newsvendor problem have been documented in the literature (Gallego and Moon 1993, Lau and Lau 1996, 1997, Khouja 1999, Petruzzi and Dada 1999, Cachon 2003, Shore 2004, Qin et al. 2011). The inferences drawn from this problem aids inventory decision making, capacity planning, yield management, and supply chain contracts in various industries that handle shorter life-cycle products, for example, fashion apparel industries, insurance, hospitality, sporting industries.

In its classical formulation, a decision maker facing stochastic demand must decide his stocking quantity for a single selling period, in order to maximize his expectedprofit. Let he purchases goods at per unit price $c$, sells at $p>$ $c$, and salvages the unsold goods at $s<c$. If he places the order quantity $q$, then his realized profit per period is given by

$$
\begin{aligned}
& \pi(q, x)=(p-c) \min \{q, x\} \\
& \quad-\max \{0,(c-s)(q-x)\} \\
& \text { after some simplification, the expected-profit is } \\
& \qquad \begin{aligned}
E[\pi(q, x)]=(1-F(q)) \pi(q, q) \\
+
\end{aligned} \\
& +\int_{0}^{q} f(x) \pi(q, x) d x
\end{aligned}
$$

where, demand is denoted by a random variable $x$ which is continuous over $[0, \infty]$, with $f($.$) and F($.$) as its probability$ density function and cumulative distribution function, respectively. Since, equation (2) is strictly concave in $q$, hence the unique optimal order quantity $q^{*}$ that maximizes equation (2) can be calculated and is thus, given by

$$
q^{*}=F^{-1}\left[\frac{p-c}{p-s}\right]
$$

This optimality condition is the well-known "critical fractile" formula. To investigate the newsvendor decisions across different profit conditions, Schweitzer and Cachon (2000) used this fractile to classify the goods as high profitmargin: when $(p-c) /(p-s) \geq 0.5$ and low profit-margin good: when $(p-c) /(p-s)<0.5$, respectively. The authors assumed a symmetric demand distribution and showed that the optimal order quantity is above mean demand for high profit-margin good and below mean demand for low profit-margin good. In the next section, we present our research methodology, followed by discussions on analysis of the various behavioral theories and biases in newsvendor problem, in the upcoming sections.

\section{RESEARCH METHODOLOGY}

The objective of this paper is first to identify the various behavioral theories and biases that explain the newsvendor behavior by employing a literature review. Second, to classify and analyze the identified literature from three dimensions of human behavior namely: individual decisionmaking biases, social preferences, and cultural aspects, and thereafter, suggesting the directions for future research. A literature review is essentially an appropriate tool to discover the conceptual content of the field and structuring it to identify the gaps and issues for the future study (Meredith 1993). In this paper, we use systematic literature review, as a valid methodological approach, for the reason that it identifies key contributions to the field and adopts a transparent and replicable process, aiming at minimizing biases through exhaustive literature searches (Tranfield et al. 2003, Basnet and Seuring 2016). This serves our purpose, as the articles required to analyze in this research does not have the confined boundaries within the field of operations management/ operations research, but it also expands to several other disciplines like psychology, behavioral sciences, and behavioral economics. In this paper, we provide a review of peer-reviewed articles published in leading journals from 2000 to 2017 . The systematic literature review methodology presented in this paper is based on the seminal works of Tranfield et al. (2003), Thorpe et al. (2005), Matthews and Marzec (2012). The review process consists of four stages and the flow is shown in Table 1. 
Table 1 Summarizing systematic review process (adapted from Thorpe et al. 2005, Matthews and Marzec 2012)

\begin{tabular}{|c|c|c|c|}
\hline Stage one & Stage two & Stage three & Stage four \\
\hline Identify database & $\begin{array}{l}\text { Identify search terms } \\
\text { and citation searches }\end{array}$ & Exclusion analysis & $\begin{array}{l}\text { Identify behavioral theories and decision } \\
\text { biases }\end{array}$ \\
\hline Key Results & Key Results & Key Results & Key Results \\
\hline $\begin{array}{l}\text { Databases (8) } \\
\text { Journals (19) }\end{array}$ & Citations found (204) & $\begin{array}{l}\text { Special issues and } \\
\text { editorials (2) } \\
\text { Not focused on } \\
\text { Newsvendor problem } \\
\text { (122) } \\
\text { Does not consider } \\
\text { behavioral aspect in } \\
\text { newsvendor (32) } \\
\text { Literature reviews (4) } \\
\text { Others unrelated (3) }\end{array}$ & $\begin{array}{l}\text { Behavioral theories, judgment and decision } \\
\text { biases in decision making, heuristics. }\end{array}$ \\
\hline Identify journals & $\begin{array}{l}\text { Journal search } \\
\text { (204 citations) }\end{array}$ & $\begin{array}{c}\text { Exclusion } \\
\text { analysis (163 } \\
\text { citations) }\end{array}$ & $\begin{array}{l}\text { Behavioral theories and decision } \\
\text { biases: risk aversion, loss aversion and } \\
\text { reference dependence (prospect } \\
\text { theory), waste aversion, stockout } \\
\text { aversion, underestimated opportunity } \\
\text { costs, ex-post inventory minimization, } \\
\text { anchoring and insufficient adjustment, } \\
\text { bounded rationality, overconfidence, } \\
\text { law of small numbers, learning effects, } \\
\text { fairness, cultural aspects }\end{array}$ \\
\hline
\end{tabular}

\subsection{Stage One: Identify Database}

Identification of the relevant journals and databases is the first step of our systematic review process. To initiate the identification of suitable articles, we used a variety of Edatabases like ABI/Inform (Proquest), EBSCO, Emerald Insight, Science Direct (Elsevier), Scopus, Springer Link, Taylor \& Francis, and Web of Science. Also, some articles were identified from Google Scholar and the special issues on behavioral operations to expand the breadth of our search further. As the major contributions are more likely to come from leading journals (Webster and Watson 2002) we selected the articles from well-accredited peer-reviewed top journals of operations management that are listed in Australian Business Dean Council Journal Quality List 2016 (http://www.abdc.edu.au/index.php) and have substantially higher citation-indexes. Additionally, to reveal the behavioral aspects, we have taken two more journals from the field of psychology and decisions; they are Decision Support Systems and Organizational Behavior and Human Decision Processes. Table 2 lists the selected journals. The starting point of the time horizon for selection of articles is from 2000 to 2017 . The year 2000 is selected as the starting point due to the publication of seminal work of Schweitzer and Cachon (2000). To our knowledge, this was the first article that conducted human controlled experiments to disentangle biases in newsvendor context. Since then, a significant amount of literature has emerged in newsvendor settings, to theoretically and empirically understand the inventory decisions that are evidenced in observed findings.

\subsection{Stage Two: Identify Search Terms and Citation Searches}

The second stage is to identify the search terms and citation searches in the above selected journals. We set the title, abstract and keywords as the search criteria in Edatabases. First, we identified a certain number of generic keywords like "behavioral operations", "newsvendor problem", and "decision biases" from the extant literature. To further enhance the collection of our keywords we asked the experts, the professors, and scanned through the table of contents of chosen journals that resulted in adding a few more keywords like "fairness", "experimental economics", "modeling behavior", "inventory management" to our list. These keywords returned 180 articles, without reproducibility and repetitions. To further accelerate the search for relevant articles, citations in the above chosen articles were reviewed by going backward to the original papers. This is consistent with the approach of Webster and Watson (2002). We added more papers by identifying the articles that are citing the articles identified in the previous step. 
Table 2 Selected peer-reviewed journals from ABDC Journal Quality List 2016

Table 2 Selected peer-reviewed journals from ABDC Journal Quality List 2016

$\begin{array}{llll}\text { Journals } & \text { ABDC } & \text { Databases used } & \begin{array}{c}\text { No. of } \\ \text { articles }\end{array}\end{array}$

\begin{tabular}{|c|c|c|c|}
\hline Journal of Operations Management & $A^{*}$ & $\begin{array}{l}\text { Science Direct } \\
\text { (Elsevier) }\end{array}$ & 3 \\
\hline Production and Operations Management & $A$ & EBSCO & 7 \\
\hline Manufacturing and Service Operations & A & EBSCO & 6 \\
\hline Management Science & $A^{*}$ & Web of Science & 6 \\
\hline Decision Sciences & $A^{*}$ & Scopus & 1 \\
\hline Omega & $A^{*}$ & $\begin{array}{l}\text { Science Direct } \\
\text { (Elsevier) }\end{array}$ & 2 \\
\hline Organizational Behavior and Human Decision Processes & $A^{*}$ & Scopus & 1 \\
\hline European Journal of Operational Research & $A^{*}$ & Web of Science & 4 \\
\hline Operations Research & $A^{*}$ & Scopus & 2 \\
\hline Operations Research Letters & A & Scopus & 1 \\
\hline Journal of Operational Research Society & A & Springer Link & 3 \\
\hline Annals of Operations Research & A & Springer Link & 0 \\
\hline Decision Support Systems & $A^{*}$ & $\begin{array}{l}\text { Science Direct } \\
\text { (Elsevier) }\end{array}$ & 1 \\
\hline International Journal of Physical Distribution of Logistics and Management & A & Emerald Insight & 0 \\
\hline International Journal of Operations and Production Management & A & Emerald Insight & 0 \\
\hline Journal of Supply Chain Management & A & ABI/Inform (Proquest) & 0 \\
\hline International Journal of Production Economics & $A^{*}$ & $\begin{array}{l}\text { Science Direct } \\
\text { (Elsevier) }\end{array}$ & 2 \\
\hline International Journal of Production Research & $A$ & Taylor \& Francis & 2 \\
\hline Supply Chain Management: An International Journal & $A$ & Emerald Insight & 0 \\
\hline Transportation Research Part E: Logistics and Transportation Review & $A^{*}$ & $\begin{array}{l}\text { Science Direct } \\
\text { (Elsevier) }\end{array}$ & 0 \\
\hline Total & & & 41 \\
\hline
\end{tabular}

This is called go forward approach (Webster and Watson 2002). So, finally, we found 24 more articles that resulted in a total of 204 articles by the end of this stage (Table 1).

\subsection{Stage Three: Exclusion Analysis}

The objective of this step is to identify and eliminate those articles that do not meet the criteria of our research, which is to choose the articles that essentially consider the influence of human behavior on inventory decisions in the newsvendor problem setting. To identify this, we read the abstracts and full texts of articles selected in the previous step with the aim of exclusion of unwanted articles. Any kind of duplicities in the articles had already been removed during stage two of the review process. Because we used "behavioral operations" as one of the keywords in our search, we found many articles which were from other areas of operations, but their primary focus was not on the newsvendor problem. In this way, we removed 122 articles (Craighead et al. 2009). 9 articles were excluded because they were not in-line with the primary objective of our research and were either the part of special issues, editorials, literature reviews, and other unrelated areas. We also disqualified 32 articles because they did not consider 
behavioral aspect as the core attention in the newsvendor problem setting. In sum, a total of 163 articles were excluded in overall exclusion analysis, resulting in 41 papers for the review.

\subsection{Stage Four: Identify Behavioral Theories and Decision Biases}

Finally, in the fourth stage, we identified which behavioral theories, decision biases, and human preferences have been documented in the literature, to examine the observed findings on inventory decision making behavior in newsvendor setting. We explored some judgment and decision biases, heuristics that people adapt to take their decisions under uncertainty. Consequently, we classified and analyzed the identified behavioral theories and biases from three dimensions of human behavior: individual decision making, social preferences, and cultural aspects (Fig. 1). These are further discussed in the next section.

\section{ANALYSIS OF THE BEHAVIORAL THEORIES AND BIASES IN NEWSVENDOR DECISION MAKING}

In the following section, we present the analysis of the papers, which we have undertaken for this review. Tables are used to communicate significant outcomes and understandings from the articles. To incorporate the people issues into the problems of operations management, Loch and Wu (2007) classify human behavior that goes beyond normative predictions into three dimensions:

a) Decision making biases in individuals due to their cognitive limitations. b) Behavior with regard to the social interactions driven by social preferences.

c) Impact of embedded culture on the collective thoughts and behaviors in a population.

Croson et al. (2013) also reflect upon these three dimensions in their review of behavioral operations, for the articles published from 2006 to 2011. We use this approach to conceptualize human behavior in newsvendor context. This allows an organized and comprehensive investigation into the behaviors that affect inventory ordering decisions. Hence, this paper focuses on the classification of people issues into above three dimensions (Fig. 1).

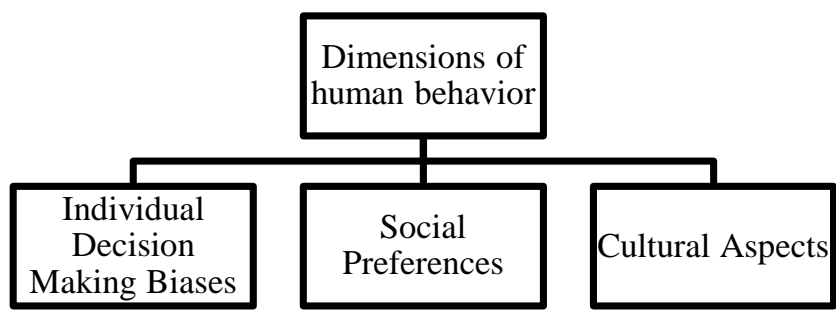

Figure 1 Classifying human behavior into three dimensions (Loch and $\mathrm{Wu} 2007$ )

Our findings from the review show that research has primarily emphasized individual decision-making biases while social and cultural aspects lack analysis and are worthy of investigation. Also, we did not find any article that exclusively integrates all three dimensions of human behavior. Following, we discuss the most prevalent behavioral theories and biases, identified in the literature and illustrate how they have been used in explaining observed empirical findings. Table 3 summarizes our findings.

Table 3 Summarising behavioral theories and biases found in the literature

\begin{tabular}{|c|c|c|c|c|}
\hline $\begin{array}{l}\text { Dimensions of } \\
\text { human behavior }\end{array}$ & $\begin{array}{c}\text { Behavioral } \\
\text { theories and } \\
\text { biases }\end{array}$ & Description & Newsvendor settings & $\begin{array}{l}\text { Literature/related } \\
\text { papers }\end{array}$ \\
\hline \multirow[t]{2}{*}{$\begin{array}{l}\text { 1. Individual } \\
\text { decision } \\
\text { biases }\end{array}$} & $\begin{array}{l}\text { Risk-seeking } \\
\text { and risk } \\
\text { aversion }\end{array}$ & $\begin{array}{l}\text { Risk-seeking: choice } \\
\text { preference of higher } \\
\text { uncertainty } \\
\text { Risk-aversion: choice } \\
\text { preference of lower } \\
\text { uncertainty }\end{array}$ & $\begin{array}{l}\text { Risk seeking: newsvendor will } \\
\text { order higher than the risk- } \\
\text { neutral profit maximizing } \\
\text { quantity }\left(\mathrm{q}>\mathrm{q}^{*}\right) \\
\text { Risk aversion: newsvendor will } \\
\text { order lower than the risk- } \\
\text { neutral profit maximizing } \\
\text { quantity }\left(\mathrm{q}<\mathrm{q}^{*}\right)\end{array}$ & $\begin{array}{l}\text { Schweitzer and Cachon } \\
\text { (2000), Eeckhoudt et al. } \\
\text { (1995), Agrawal and } \\
\text { Seshadri (2000), Wang et } \\
\text { al. (2009), Keren and } \\
\text { Pliskin (2006), Gaur and } \\
\text { Seshadri (2005), Chen et } \\
\text { al. (2007), De Véricourt } \\
\text { et al. (2013), Choi et al. } \\
\text { (2011), Choi and } \\
\text { Ruszczyński (2011), } \\
\text { Gavirneni and Robinson } \\
\text { (2017), Wu et al. (2014), } \\
\text { Dai and Meng (2015) }\end{array}$ \\
\hline & $\begin{array}{l}\text { Reference- } \\
\text { dependence } \\
\text { (Prospect } \\
\text { Theory) }\end{array}$ & $\begin{array}{l}\text { Valuation of outcome is } \\
\text { derived from the amount } \\
\text { of deviation from chosen } \\
\text { reference point }\end{array}$ & $\begin{array}{l}\text { Newsvendor will be risk- } \\
\text { seeking }\left(\mathrm{q}>\mathrm{q}^{*}\right) \text { over } \\
\text { negative deviation (Loss } \\
\text { domain) and risk-averse }(\mathrm{q}< \\
\left.\mathrm{q}^{*}\right) \text { over positive deviation } \\
\text { (Gain domain) }\end{array}$ & $\begin{array}{l}\text { Schweitzer and Cachon } \\
\text { (2000), Herweg (2013), } \\
\text { Nagarajan and Shechter } \\
\text { (2013), Long and Nasiry } \\
\text { (2014), Uppari and Hasija } \\
\text { (2014), Zhao and Geng } \\
\text { (2015), Li et al. (2017), } \\
\text { Liu et al. (2017), }\end{array}$ \\
\hline
\end{tabular}




\begin{tabular}{|c|c|c|c|c|}
\hline $\begin{array}{l}\text { Dimensions of } \\
\text { human behavior }\end{array}$ & $\begin{array}{l}\text { Behavioral } \\
\text { theories and } \\
\text { biases }\end{array}$ & Description & Newsvendor settings & $\begin{array}{l}\text { Literature/related } \\
\text { papers }\end{array}$ \\
\hline & & & & $\begin{array}{l}\text { Kahneman and Tversky } \\
\text { (1979) }\end{array}$ \\
\hline & Loss-aversion & $\begin{array}{l}\text { tendency of decision } \\
\text { maker to strongly prefer } \\
\text { avoiding losses than } \\
\text { deriving equal amount of } \\
\text { gains }\end{array}$ & $\begin{array}{l}\text { loss averse newsvendor will } \\
\text { prefer orders that strictly } \\
\text { generate profits }\left(\mathrm{q}<\mathrm{q}^{*}\right)\end{array}$ & $\begin{array}{l}\text { Wang and Webster } \\
\text { (2009), Schweitzer and } \\
\text { Cachon (2000), Wang } \\
\text { (2010) }\end{array}$ \\
\hline & $\begin{array}{l}\text { Waste- } \\
\text { aversion }\end{array}$ & $\begin{array}{l}\text { Tendency of decision } \\
\text { maker to strongly dislike } \\
\text { carrying excess inventory } \\
\text { at the end of season }\end{array}$ & $\begin{array}{l}\text { Newsvendor will be charged } \\
\text { extra penalty for each unit of } \\
\text { leftover inventory, so he would } \\
\text { order less than optimal quantity } \\
\left(\mathrm{q}<\mathrm{q}^{*}\right)\end{array}$ & $\begin{array}{l}\text { Schweitzer and Cachon } \\
\text { (2000), Arkes (1996) }\end{array}$ \\
\hline & $\begin{array}{l}\text { Stock-out } \\
\text { aversion }\end{array}$ & $\begin{array}{l}\text { Tendency of decision } \\
\text { maker to dislike the lost } \\
\text { sales }\end{array}$ & $\begin{array}{l}\text { Newsvendor will be charged } \\
\text { goodwill penalty for each unit of } \\
\text { lost sales due to unsatisfied } \\
\text { demand, so he would order } \\
\text { more than optimal quantity } \\
\left(q>q^{*}\right)\end{array}$ & $\begin{array}{l}\text { Schweitzer and Cachon } \\
(2000)\end{array}$ \\
\hline & $\begin{array}{l}\text { Underestimat } \\
\text { ed opportunity } \\
\text { costs }\end{array}$ & $\begin{array}{l}\text { Tendency of decision } \\
\text { maker to undervalue } \\
\text { opportunity costs if he } \\
\text { discounts the marginal } \\
\text { value associated with } \\
\text { forgone sales }\end{array}$ & $\begin{array}{l}\text { Newsvendor that } \\
\text { underestimate opportunity cost } \\
\text { will order less than optimality } \\
\left(\mathrm{q}>\mathrm{q}^{*}\right)\end{array}$ & $\begin{array}{l}\text { Schweitzer and Cachon } \\
(2000)\end{array}$ \\
\hline & $\begin{array}{l}\text { Ex-post } \\
\text { inventory } \\
\text { minimization }\end{array}$ & $\begin{array}{l}\text { Tendency of decision } \\
\text { maker to feel regret for the } \\
\text { difference between their } \\
\text { order quantity and realized } \\
\text { demand }\end{array}$ & $\begin{array}{l}\text { For the symmetric cumulative } \\
\text { demand function about mean, } \\
\text { a newsvendor will exhibit "pull } \\
\text { to center" effect }\end{array}$ & $\begin{array}{l}\text { Schweitzer and Cachon } \\
\text { (2000), Bostian et al. } \\
(2008), \text { Kremer et al. } \\
(2010,2014), \text { Bell (1982, } \\
\text { 1985), Loomes and } \\
\text { Sugden }(1982,1987)\end{array}$ \\
\hline & $\begin{array}{l}\text { anchoring and } \\
\text { insufficient } \\
\text { adjustment } \\
\text { bias }\end{array}$ & $\begin{array}{l}\text { tendency of decision } \\
\text { maker to use a reference } \\
\text { point, or 'anchor' and then } \\
\text { insufficiently adjusting } \\
\text { away from this anchor }\end{array}$ & $\begin{array}{l}\text { two alternative anchors: } \\
\text { - mean anchor heuristic, } \\
\text { and, } \\
\text { - previous demand chasing } \\
\text { heuristic }\end{array}$ & $\begin{array}{l}\text { Schweitzer and Cachon } \\
\text { (2000), Benzion et al. } \\
\text { (2008), Bolton and Katok } \\
\text { (2008), Bostian et al. } \\
\text { (2008), Lurie and } \\
\text { Swaminathan (2009), } \\
\text { Gavirneni and Xia (2009), } \\
\text { Lau and Bearden (2013), } \\
\text { Moritz et al. (2013), Lau } \\
\text { et al. (2014), Zhao et al. } \\
\text { (2016), D'Urso et al. } \\
\text { (2017), Gavirneni and } \\
\text { Robinson (2017), } \\
\text { Kahneman et al. (1982) }\end{array}$ \\
\hline & $\begin{array}{l}\text { bounded } \\
\text { rationality }\end{array}$ & $\begin{array}{l}\text { limited rationality of } \\
\text { decision makers due to } \\
\text { their cognitive limitations, } \\
\text { insufficient information, } \\
\text { time and cost constraints }\end{array}$ & $\begin{array}{l}\text { a boundedly rational } \\
\text { newsvendor chooses an order } \\
\text { quantity which is more } \\
\text { satisficing rather than optimal, } \\
\text { i.e. he chooses high yielding } \\
\text { order quantities with larger } \\
\text { probability }\end{array}$ & $\begin{array}{l}\text { Simon (1955), Su (2008), } \\
\text { Kremer et al. (2010), } \\
\text { Katok (2011), } \\
\text { (Ovchinnikov et al. 2015) }\end{array}$ \\
\hline & $\begin{array}{l}\text { overconfidenc } \\
\text { e bias (or, } \\
\text { overprecision) }\end{array}$ & $\begin{array}{l}\text { tendency of decision } \\
\text { maker to overestimate } \\
\text { their own opinions due to } \\
\text { precise information that } \\
\text { they believe they have }\end{array}$ & $\begin{array}{l}\text { An overconfident newsvendor } \\
\text { will underestimate the variance } \\
\text { of demand and make } \\
\text { suboptimal ordering decisions. } \\
\text { Over-order in low profit-margin }\end{array}$ & $\begin{array}{l}\text { Croson et al. (2008), Ren } \\
\text { and Croson (2013), Ren } \\
\text { et al. (2017) }\end{array}$ \\
\hline
\end{tabular}




\begin{tabular}{|c|c|c|c|c|}
\hline $\begin{array}{l}\text { Dimensions of } \\
\text { human behavior }\end{array}$ & $\begin{array}{l}\text { Behavioral } \\
\text { theories and } \\
\text { biases }\end{array}$ & Description & Newsvendor settings & $\begin{array}{l}\text { Literature/related } \\
\text { papers }\end{array}$ \\
\hline & & & $\begin{array}{l}\text { condition and under-order in } \\
\text { high profit-margin condition }\end{array}$ & \\
\hline & $\begin{array}{l}\text { law of small } \\
\text { numbers }\end{array}$ & $\begin{array}{l}\text { Tendency to generalize } \\
\text { about the characteristics } \\
\text { of population from a small } \\
\text { data size }\end{array}$ & $\begin{array}{l}\text { A newsvendor may choose } \\
\text { order quantity based on } \\
\text { insufficiently small sample }\end{array}$ & $\begin{array}{l}\text { Tversky and Kahneman } \\
\text { (1971), Bolton and Katok } \\
\text { (2008) }\end{array}$ \\
\hline & $\begin{array}{l}\text { learning } \\
\text { effects }\end{array}$ & $\begin{array}{l}\text { Decision makers tends to } \\
\text { learn from the feedback } \\
\text { and experience }\end{array}$ & $\begin{array}{l}\text { A newsvendor learning from } \\
\text { frequent feedbacks and } \\
\text { experience may order close to } \\
\text { optimal solution }\end{array}$ & $\begin{array}{l}\text { Bostian et al. (2008), } \\
\text { Bolton and Katok (2008), } \\
\text { Lurie and Swaminathan } \\
(2009)\end{array}$ \\
\hline $\begin{array}{ll}2 . & \text { Social } \\
& \text { Preferences }\end{array}$ & $\begin{array}{l}\text { fairness (or, } \\
\text { inequity } \\
\text { aversion) }\end{array}$ & $\begin{array}{l}\text { decision maker's care for } \\
\text { the relevant people } \\
\text { around him/her, decrease } \\
\text { in the overall utility of the } \\
\text { decision maker due to } \\
\text { deviations from parity }\end{array}$ & $\begin{array}{l}\text { the increasing concerns of } \\
\text { newsvendor about the fairness } \\
\text { with supplier may result in } \\
\text { improving the system efficiency }\end{array}$ & $\begin{array}{l}\text { Kahneman et al. (1986), } \\
\text { Cui et al. (2007), } \\
\text { Demirag et al. (2010), } \\
\text { Wu and Niederhoff } \\
\text { (2014), Du et al. (2014) }\end{array}$ \\
\hline $\begin{array}{l}\text { 3. } \\
\text { Cultural } \\
\text { Aspects }\end{array}$ & cross-national & $\begin{array}{l}\text { knowledge and skills } \\
\text { acquired by decision } \\
\text { maker are influenced by } \\
\text { national and regional } \\
\text { culture of the market }\end{array}$ & $\begin{array}{l}\text { ordering pattern of newsvendor } \\
\text { is affected by cross-cultural } \\
\text { differences }\end{array}$ & $\begin{array}{l}\text { Feng et al. (2011), Cui et } \\
\text { al. (2013) }\end{array}$ \\
\hline
\end{tabular}

\subsection{Individual Decision-Making Biases}

Schweitzer and Cachon (2000) found that the PTC effect observed in their experimental data results were not consistent with alternatives like risk aversion preferences, loss aversion, waste aversion bias, stock out aversion, or underestimating opportunity costs (Table 3), instead they found two explanations for this behavior: (1) individual's preferences to reduce ex-post inventory error; and (2) subjects suffer from anchoring and insufficient adjustment bias. Ex-post inventory refers to the tendency of the decision maker to feel disappointment for the difference between their ordered quantity and realized demand (Bell 1982, 1985). Bostian et al. (2008) incorporated regret error terms in their study and also confirmed minimization of ex-post inventory error as bias in inventory decisions. Katok et al. (2014) posit that demand information mitigates regret from ex-post inventory errors. Schweitzer and Cachon (2000) found that a decision maker adopts anchoring and insufficient adjustment heuristics to choose their order quantities. It implies their tendency to use a reference point, or 'anchor' and then insufficiently adjusting away from this anchor. The authors considered two alternative anchors: mean anchoring heuristic, and demand chasing heuristic. Former refers to anchoring on the expected demand and then adjusting towards optimal quantity, whereas latter refers anchoring on prior order quantity and then adjusting towards prior demand. The authors predicted only the adjustment patterns and not how the anchor is initially selected. Gavirneni and Xia (2009) found that decision maker would anchor close to the optimal solution when he has multiple pieces of information available.

Benzion et al. (2008) investigated the impact of demand information on order choices. They conducted an experiment where participants were provided with the knowledge of demand parameters and found that demand information is not a significant factor in decision making.
Bolton and Katok (2008) further intervened into decision maker's experience and feedback that might help in decisions. They investigated the anchoring around the expected demand and showed that longer experience slowly increases the probability of placing the optimal orders. They also found that individuals are prone to make "law of small number' bias, i.e., they tend to choose the order quantity based on inappropriately small samples and results in decreased performance. Lurie and Swaminathan (2009) also examined the impact of frequency of feedback on ordering decisions and found that beyond a certain range, feedback frequency may have a negative effect on player's performance. Lau et al. (2014) examined the experimental data of Bolton and Katok (2008) and pointed out an important observation regarding PTC effect. They showed that while PTC effect is present in aggregate data, it does not sufficiently describe a population of individual decision makers and hence, does not account for heterogeneity in individual behavior. Consistent with this study, recently, D'Urso et al. (2017) analyzed the individual behavior across the newsvendor game and showed that when the demand distribution is not known, and the only information available is about the previously realized demands, then the decision makers make larger adjustments in demand chasing heuristics. Following we discuss the identified themes in the literature that describe decision making of individuals.

\subsubsection{Risk Aversion}

Risk aversion is often used as an alternate choice model to explain the reasonable evidence when individuals fail to correspond to risk-neutral expected profit-maximizing orders. Eeckhoudt et al. (1995) used expected utility theory framework to model risk aversion in newsvendor decision making. Agrawal and Seshadri (2000) studied the impact of increasing risk aversion on order quantity and price-setting decisions of the retailer, who faces different price-dependent 
demand function namely: multiplicative form, and additive form. They found that for the multiplicative form of demand, a risk-averse newsvendor will set a higher price and will place lesser order quantity than the risk-neutral choice. And for the case of additive form of demand, a risk-averse newsvendor will set a lower price, while his order quantity would depend upon demand elasticity. Similar evidence is provided by Wang et al. (2009) who extended upon Eeckhoudt et al. (1995) and showed that a risk-averse newsvendor would order less as the selling price goes beyond a threshold value. Keren and Pliskin (2006) calculated the closed form optimal solution for risk-averse newsvendor problem, under uniform demand distribution. Gaur and Seshadri (2005) examined that when demand and price of a financial asset are correlated, then a risk-averse newsvendor hedges the inventory risk and orders more inventory.

Several researchers have studied multi-period and multi-product newsvendor problem under risk aversion. Chen et al. (2007) examined structural analysis of optimal policy inventory policies and computationally demonstrated that the optimal policy is relatively not sensitive to the small changes in risk aversion level of decision maker. Choi et al. (2011) showed that for a portfolio of identical products with independent demands, the risk aversion results in decreased orders. They also showed that for the positively related dependent demands, a risk-averse newsvendor would order lower optimal order quantities than the independent demands, and vice-versa. De Véricourt et al. (2013) explained gender differences in risk preferences in newsvendor ordering decisions. They showed that in high margin settings, males order more than females, implying more risk-seeking appetite in males than females. They did not find any significant differences in low margin settings. Recently, Gavirneni and Robinson (2017) showed that riskaversion and implicit shortage cost could comprehensively explain anchoring and insufficient bias. Some studies have also explored risk-aversion in newsvendor model under CVaR risk measure criterion. Wu et al. (2014) considered risk-aversion under quantity and price competition. Since both of these competitive environments lead to overstocking under risk-neutral criterion, but authors found that riskaversion could mitigate these effects. They found that riskaversion could mitigate overstocking due to competition. Dai and Meng (2015) analyzed joint ordering decision under market and price dependency. They showed that optimal order quantity increases with the marketing effort, the optimal price remains unchanged. In sum, all these studies are similar in the way to analyze the effect of deciding optimal order quantity under risk-aversion criterion in newsvendor settings.

\subsubsection{Loss Aversion and Reference Dependence (Prospect Theory)}

In recent years, the major amount of research in newsvendor problem is in explaining the ordering behavior by the loss-averse nature of the retailer (Wang and Webster 2009, Wang 2010). The bases of loss aversion bias come from prospect theory (PT) which says that amount of negative utility (or disutility) from a certain size of loss is greater than the amount of positive utility extracted from the same size of gain (Kahnemann and Tversky 1979). PT proposes that the value (or utility) derived from an outcome is defined by how far it has changed from a reference point, rather than by its final state. Increase in the value of outcome from its reference point is referred as gain and decrease as losses. This illustrates that people show a loss aversion behavior, that is, they prefer to avoid losses than acquiring gains. Schweitzer and Cachon (2000) used the common piecewise linear utility function given by:-

$$
v(y)=\left\{\begin{array}{rr}
y, & y \geq 0 \\
\lambda y, & y<0
\end{array}\right.
$$

where, $\lambda>1$ is the index of loss aversion (Köbberling and Wakker 2005). They derived that a loss-averse retailer with above utility function would order less than the profitmaximizing quantity, $q<q^{*}$. However, they found that PT lacks in completely supporting the findings of their experimental results. Nagarajan and Shechter (2014) used cumulative prospect theory (CPT) in their study, to handle the multiple outcome prospects by using probability weighting function developed by Prelec (1998), $w(p)=$ $e^{-\delta\left((-\ln p)^{\gamma}\right)}(0<\gamma<1)$. However, again they did not find any support for the PT explaining empirical findings of Schweitzer and Cachon (2000). But, later on, Long and Nasiry (2015) argued that PT could explain the ordering behavior in newsvendor problem if the reference point is not assumed to zero, as it was in earlier studies. They mathematically explained this by taking the reference point as the weighted average of the maximum and minimum possible profits. They illustrated this with linear and as well as two-part power utility function given by:

$$
v(y)=\left\{\begin{aligned}
\eta y^{\alpha}, & y \geq 0 \\
-\lambda \eta(-y)^{\alpha}, & y<0
\end{aligned}\right.
$$

where $0<\alpha<1, \eta$ denotes the strength of reference effects (Tversky and Kahneman 1992). Zhao and Geng (2015) further showed the support for PT by taking the reference point as the mid-value of highest and lowest possible profit. Uppari and Hasija (2014) highlighted the limitations of Long and Nasiry (2014)'s model and discussed that it fails on most of the theoretical and empirical criteria and violates stochastic dominance, as its reference point depends upon the ordered quantity. More importantly, Uppari and Hasija (2014) theoretically and empirically studied the five different models of prospect-dependent reference point, fixed-reference point and stochasticreference point models respectively and found that the model with mean demand as the reference point consistently dominates the other models. The other relevant related literature on loss aversion and newsvendor problem is shown in Table 4.

\subsubsection{Bounded Rationality}

Bounded rationality is not necessarily a bias; it is the concept that quality of decisions of individuals is limited due to information insufficiency, time scarcity and cognitive limitations of their minds. To investigate the PTC effect in newsvendor problem, Su (2008) proposed the model of bounded rationality. According to it, a boundedly rational newsvendor tries to maximize her expected profit but cannot determine the optimal order quantity because of the occurrence of random errors in ordering. 
Table 4 Summarizing the related literature on loss aversion and newsvendor problem

\begin{tabular}{|c|c|c|c|c|c|c|}
\hline Related work & $\begin{array}{c}\text { Nature of } \\
\text { reference point }\end{array}$ & Value function & $\begin{array}{c}\text { Probability } \\
\text { weighting } \\
\text { function }\end{array}$ & PT/CPT & $\begin{array}{c}\text { Loss } \\
\text { aversion }\end{array}$ & Method \\
\hline $\begin{array}{l}\text { Schweitzer and } \\
\text { Cachon (2000) }\end{array}$ & zero & $\begin{array}{l}\text { Piece-wise linear } \\
\text { function }\end{array}$ & - & PT & No & Lab experiment \\
\hline $\begin{array}{l}\text { Wang and Webster } \\
(2009)\end{array}$ & zero & $\begin{array}{l}\text { Piece-wise linear } \\
\text { function }\end{array}$ & - & PT & Yes & $\begin{array}{l}\text { Mathematically/ } \\
\text { theoretically }\end{array}$ \\
\hline Herweg (2013) & stochastic & $\begin{array}{l}\text { Piece-wise linear } \\
\text { function }\end{array}$ & - & PT & Yes & $\begin{array}{l}\text { Mathematically/ } \\
\text { theoretically }\end{array}$ \\
\hline $\begin{array}{l}\text { Nagarajan and } \\
\text { Shechter (2013) }\end{array}$ & zero & $\begin{array}{l}\text { Power utility } \\
\text { function }\end{array}$ & $\begin{array}{l}\text { Prelec } \\
\text { probability } \\
\text { weighting } \\
\text { function }\end{array}$ & CPT & No & $\begin{array}{l}\text { Mathematically/ } \\
\text { theoretically with } \\
\text { numerical experiment }\end{array}$ \\
\hline $\begin{array}{l}\text { Long and Nasiry } \\
\text { (2014) }\end{array}$ & $\begin{array}{l}\text { weighted average } \\
\text { of highest and } \\
\text { lowest possible } \\
\text { profit }\end{array}$ & $\begin{array}{l}\text { Piece-wise linear } \\
\text { function, Two-part } \\
\text { power utility } \\
\text { function }\end{array}$ & - & PT & Yes & $\begin{array}{l}\text { Mathematically/ } \\
\text { theoretically }\end{array}$ \\
\hline $\begin{array}{l}\text { Uppari and Hasija } \\
(2014)\end{array}$ & $\begin{array}{l}\text { min demand, } \\
\text { max demand, } \\
\text { mean demand }\end{array}$ & $\begin{array}{l}\text { Piece-wise linear } \\
\text { function }\end{array}$ & - & PT & Yes & $\begin{array}{l}\text { Theoretically and } \\
\text { empirical } \\
\text { investigation }\end{array}$ \\
\hline $\begin{array}{l}\text { Zhao and Geng } \\
\text { (2015) }\end{array}$ & $\begin{array}{l}\text { mid-value of } \\
\text { highest and } \\
\text { lowest possible } \\
\text { profit }\end{array}$ & $\begin{array}{l}\text { Power utility } \\
\text { function }\end{array}$ & $\begin{array}{l}\text { Prelec } \\
\text { probability } \\
\text { weighting } \\
\text { function }\end{array}$ & CPT & Yes & $\begin{array}{l}\text { Mathematically/ } \\
\text { theoretically with } \\
\text { computational } \\
\text { experiment }\end{array}$ \\
\hline Li et al. (2017) & non-zero & $\begin{array}{l}\text { Piece-wise linear } \\
\text { function, Two-part } \\
\text { power utility } \\
\text { function }\end{array}$ & $\begin{array}{l}\text { Prelec } \\
\text { probability } \\
\text { weighting } \\
\text { function }\end{array}$ & CPT & Yes & $\begin{array}{l}\text { Mathematically/ } \\
\text { theoretically with } \\
\text { computational results }\end{array}$ \\
\hline
\end{tabular}

The author used quantal choice theory to develop the random error model for bounded rationality and shows that choices with higher expected utilities are chosen with larger probabilities. Without touching upon the risk-neutral behavior of the decision-maker, this model predicted that the similar ordering behavior in newsvendor problem, observed in Bolton and Katok (2008), that is, the average order quantity converges toward mean demand. However, Kremer et al. (2010) tested the descriptive validity of the work of Su (2008) in a controlled lab experiment and suggested that random error explanation is insensitive to the context of decision settings and could not exclusively explain the mean ordering behavior. In their lab experiment, they found that the group of participants facing standard newsvendor problem (operation frame) were observed to be significantly more biased toward mean ordering and demand chasing than the group of participants facing standard risky choice framework (neutral frame). Katok (2011) also argued on the behavioral solution of $\mathrm{Su}$ (2008) and showed that it can predict the behavior only when the demand $q$ is truncated between two extreme points. Katok (2011) illustrated it by plotting cumulative distribution of order quantities for a not very small value of bounded rationality parameter and found that mass of subjects are overestimated at either end of the plot. This overestimation effect would further increase with the value of bounded rationality parameter in the model. So, the model fails to account for heterogeneity in the individuals and thus no single explanation for the observed behavior. Random error model of Su (2008) is also not useful for the newsvendor under competition (Ovchinnikov et al. 2015), where a decision-maker can predict some regularities in the ordering pattern of competing newsvendor by applying decision support models.

\subsubsection{Overconfidence}

To our knowledge, Croson et al. (2008) were the first to propose overconfidence (specifically, overprecision) bias as an explanation in the newsvendor decisions under uncertainty. Ren and Croson (2013) hypothesized and experimentally demonstrated that individuals underestimate the variance in consumer demand and make suboptimal decisions. They assumed that a newsvendor would accurately estimate the mean of demand but undervalue the variance in demand. Based, on this assumption of meanpreservation, but variance-reducing transformation of true demand estimation, they explained that individuals would order closer to the mean demand and would show PTC effect as observed in Schweitzer and Cachon (2000), and several other studies.

\subsection{Social Preferences}

The behavior of people is often influenced by the goals they set to accomplish, the feedback they receive toward achieving the goal and the way they build interaction with people around them (group dynamics) (Bendoly et al. 2010). Loch and Wu (2007: p 85) write that

Social preferences are systematic influences that can have as much of an effort on economic performances as rational optimization does.

Although there are many aspects of social preferences required to explore in operations management studies, we found there is only a limited number of works on newsvendor 
problem that deals with the way social interactions influence ordering decisions. Specifically, social preferences that influence inventory decisions have been analyzed with a focus on the impact of fairness concerns in the buyersupplier relationship for the better performance in newsvendor settings (Wu and Niederhoff 2014, Du et al. 2014), behavior of groups in inventory decision making and trustworthiness (Gavirneni and Xia 2009, Talavera 2014), impact of social comparison between peer buyers on their respective buying decisions (Avc1 et al. 2014).

\subsubsection{Fairness}

Fairness is one of the important aspects of relationship that influence the decisions of people. The recent development in behavioral economics has shown that the concern for fairness among the different human players may help them to motivate and regulate channel relationships (Kahneman et al. 1986, Rabin 1993, Geyskens 1998, Fehr and Gächter 2000). Cui et al. (2007) analyze how distributional fairness concerns in a simple two-tier wholesale price contract can help to mitigate double marginalization and achieve channel coordination. On the basis of "inequity aversion" model of Fehr and Schmidt (1999), the authors show that manufacturer can set a wholesale price to attain maximum channel profit and maximum channel utility, when either only the retailer or both the retailer and the supplier, are fair-minded (or, inequity averse). However, in their model, the authors assume demand as a linear function of retail price. Demirag et al. (2010) further extended this work by analyzing various other non-linear demand functions. The authors found that the exponential demand function may coordinate for a larger range of the model parameters when only the retailer is inequity averse. In contrast to the assumption of the supplier having complete information of retailer's preferences in earlier works, Katok et al. (2014) experimentally show that a wholesale price contract can also coordinate under information asymmetry when the fairness concerns of supply chain partners are strong enough. Along with distributional fairness, Ho et al. (2014) also consider peer-induced fairness in a single supplier-two fair retailer setting and found that peer-induced fairness is more salient than distributional fairness. Wu and Niederhoff (2014) analyzed the impact of fairness concerns on profit allocations and supply chain performance in the newsvendor setting with general randomdemand function. They found that, in case of fair-minded retailer and neutral supplier, the supply chain performance can be improved only when the retailer's ideal allocation to the supplier is above a threshold level, irrespective of demand variability. However, a win-win situation could be achieved when both the players are inequity averse, provided the retailer's ideal allocation to the supplier is within a certain range and demand variability is high.

\subsection{Cultural Aspects}

McAfee et al. (2002) suggest that culture is an important consideration in developing supply chain strategies. Issue such as organizational culture is of crucial importance to the operations of large organizations (Gino and Pisano 2008). But despite the importance of cultural aspect, it is the least addressed concern in the papers. A majority of the empirical studies our selected papers have been limited to U.S. and other western decision makers. We found only two empirical studies that look into the newsvendor decision making through cultural lens. One is Feng et al. (2011) who examined the cross-cultural differences between Chinese and American subjects in a newsvendor setting. The authors repeated the experience and feedback experiment of Bolton and Katok (2008) with Chinese subjects and found that Chinese subjects were more prominent to the "pull-to-center" effect than the Americans, i.e. average order quantities of Chinese subjects were significantly less in high-profit-condition and significantly more in low-profit-condition. So, the Chinese subjects are closer to the anchor of mean demand than Americans. The authors suggested that this difference of ordering pattern is because of the doctrine of the mean philosophy in Chinese culture, i.e. 'going too far is as bad as not going far enough'. The second cultural study we found is Cui et al. (2013) where the authors have repeated Gavirneni and Isen (2010) experiment on newsvendor by comparing the ordering decisions of Chinese in one group and Americans in the other. Though they do not find any significant difference in the effectiveness of the final ordering decisions of the two groups, however, there was the difference in how these groups make decisions across the different phases of newsvendor decisions. They found that Chinese are more competitive in quantitatively analyzing and abstracting the problem and are able to perform better in terms of profitability. Anchoring and adjustment heuristic used by Chinese subjects is only to a smaller degree. Comparing the use of salvage value between American and Chinese subjects, Chinese give more importance to salvage value, while taking their ordering decisions. This resulted in Chinese ordering more than Americans. In sum, how cultural aspects may affect inventory decisions has received relatively very less consideration.

\section{DISCUSSION AND PROPOSED FUTURE RESEARCH DIRECTIONS}

In the previous sections, we have summarized the related literature that seeks to describe the inventory ordering decisions that differs from the expected profit-maximizing quantity in the newsvendor problem. Following up on the findings and insights generated from synthesizing the previous contributions, in this section, we discuss several opportunities for future research and probable extensions for the analysis of underlying human behavioral causes in decision making in the newsvendor setting. These are as follows.

- Since there could not be a single antecedent for the observed suboptimal ordering behavior, it would be of interest to go into more depth and understand the systematic ordering patterns, both at individual and at the aggregate level that allows maximum heterogeneity to explore. Lau et al. (2014) also showed that how individuals do not tend to demonstrate PTC effect, which otherwise has been observed at the aggregate level. 
- Prior research has been limited to single-product, single-period newsvendor problem, zero-lead time assumption and leave room for studying ordering behavior in multi-item, multi-period and under stochastic lead time.

- Supplier behavior in pricing decisions (e.g., the wholesale price) is generally not considered in the newsvendor setting. Wu and Niederhoff (2014) showed how the system efficiency is more affected by the supplier's fairness concerns than retailer's. This provides other opportunities to further investigate supplier's behavior such as risk aversion and other behavioral tendencies/biases that could explain supplier behavior.

- Furthermore, advancing the present models of channel relationships with consideration of information asymmetry in cost, market forces, or demand parameters, as well as competition that would affect the buyer's ordering behavior.

- Apart from fairness concerns, the investigation into other social preferences like status-seeking, reciprocity and relationships, trust, and the effect of group identities on inventory decisions may also be pertinent to study.

- It is evident that cultural aspect is widely ignored in the extant literature. However, we need to consider more comprehensive settings that include cultural variants and explain cross-cultural differences in inventory ordering decisions. Feng et al. (2011) also suggested examining operational decisions to conduct crossnational studies using verbal protocol analysis.

- Further research may also test the effects of social preferences across cultures, which is highly relevant in global context.

Also, in the majority of empirical papers, we see that while conducting an experiment, the demand is considered as uniform distribution. One of the possible reasons behind this is that keeping demand as uniform makes the problem more easily comprehensible by the participants. While it is also quite simpler to solve the mathematical models with uniform demand, yet extending to a wider range of demand functions bring more robustness to the models.

One of the other important observations during our research is that in most of the lab studies it is the management students who have taken part as the subjects in the experiment. Though they can be considered as the representatives of the managers taking decisions in the firm, still we believe that by doing this we could not understand the entire dynamics of the individual cognizance while making decisions. More insights could come if we directly conduct the experiment with the professionals and practitioners because they are much highly exposed to the different situations in an organization. In cultural aspect, we found only two empirical studies by using Chinese subjects. The research in culture could bring more diversity in understanding the ordering behavior of individuals who come from different national backgrounds. For example, there are enough studies on Japanese culture and how they brought JIT as a successful way to do production operations. Creating hypothesis from their culture and testing it in newsvendor settings could be one of the important future research to explore, regarding cultural aspect.

\section{LIMITATIONS AND CONCLUSIONS}

The main contribution of this paper is to provide a comprehensive review of the previous empirical and analytical studies of peer-reviewed journal publication that investigate the newsvendor decision making when they use judgments other than their expected profit-maximizing solution. The vast literature has been assessed and classified into three major dimensions of human behavior, namely, individual decision making biases, social preferences, and cultural aspects that evolve individual behavior (Loch and $\mathrm{Wu}, 2007)$. Then, under this classification, we have reviewed some important behavioral theories and judgment biases that can explain the decision maker's preferences to choose the order quantities that differ from expected profit maximizing quantities. It is evident from our review that individual decision biases have been extensively studied in the newsvendor context, while there has been limited research in social preferences and cultural aspects. The findings of the paper propose several future research directions for academicians and practitioners to further contribute to this field and benefit their organizations respectively.

To the best of our knowledge, this paper is the first in the newsvendor problem literature which specifically contribute to discussions on the impact of human behavior on inventory decision making. The limitation of this paper is that the literature found on studying behavior in newsvendor problem is categorized into three dimensions of human behavior, based on Loch and Wu (2007). Yet, it is obvious that inclusion of different frameworks to provide a lens to literature analysis on newsvendor problem can further add to probable areas of future research.

\section{REFERENCES}

Agrawal, V., and Seshadri, S. (2000). Impact of uncertainty and risk aversion on price and order quantity in the newsvendor problem. Manufacturing and Service Operations Management, 2(4), pp. 410-423.

Arkes, H. R. (1996). The psychology of waste. Journal of Behavioral Decision Making, 9(3), pp. 213-224.

Avc1, B., Loutfi, Z., Mihm, J., Belavina, E., and Keck, S. (2014). Comparison as incentive: Newsvendor decisions in a social context. Production and Operations Management, 23(2), pp. 303-313.

Basnet, C., and Seuring, S. (2016). Demand-oriented supply chain strategies - A review of the literature. Operations and Supply Chain Management: An International Journal, 9(2), pp. 73-89.

Bell, D. E. (1982). Regret in decision making under uncertainty. Operations Research, 30(5), pp. 961-981.

Bell, D. E. (1985). Disappointment in decision making under uncertainty. Operations Research, 33(1), pp. 1-27.

Bendoly, E., Croson, R., Goncalves, P., and Schultz, K. (2010). Bodies of knowledge for research in behavioral operations. Production and Operations Management, 19(4), pp. 434-452.

Bendoly, E., Donohue, K., and Schultz, K. L. (2006). Behavior in operations management: Assessing recent findings and revisiting old assumptions. Journal of Operations Management, 24(6), pp. 737-752. 
Benzion, U., Cohen, Y., Peled, R., and Shavit, T. (2008). Decision-making and the newsvendor problem: an experimental study. Journal of the Operational Research Society, 59(9), pp. 1281-1287.

Bolton, G. E., and Katok, E. (2008). Learning by doing in the newsvendor problem: A laboratory investigation of the role of experience and feedback. Manufacturing and Service Operations Management, 10(3), pp. 519-538.

Bostian, A. A., Holt, C. A., and Smith, A. M. (2008). Newsvendor "pull-to-center" effect: Adaptive learning in a laboratory experiment. Manufacturing and Service Operations Management, 10(4), pp. 590-608.

Cachon, G. P. (2003). Supply chain coordination with contracts. Handbooks in Operations Research and Management Science, 11, pp. 227-339.

Carlson, J. A., and O'Keefe, T. B. (1969). Buffer stocks and reaction coefficients: An experiment with decision making under risk. The Review of Economic Studies, 36(4), pp. 467-484.

Chen, X., Sim, M., Simchi-Levi, D., and Sun, P. (2007). Risk aversion in inventory management. Operations Research, 55(5), pp. 828-842.

Choi, S., and Ruszczyński, A. (2011). A multi-product riskaverse newsvendor with exponential utility function. European Journal of Operational Research, 214(1), pp. 78-84.

Choi, S., Ruszczyński, A., and Zhao, Y. (2011). A multiproduct risk-averse newsvendor with lawinvariant coherent measures of risk. Operations Research, 59(2), pp. 346-364.

Craighead, C. W., Hult, G. T. M., and Ketchen, D. J. (2009). The effects of innovation-cost strategy, knowledge, and action in the supply chain on firm performance. Journal of Operations Management, 27(5), pp. 405-421.

Croson, D., Croson, R., and Ren, Y. (2008). How to manage an overconfident newsvendor. 2008-07-23). http://cbees. utdallas, edu/papers/CrosonRenCmsonMS2008, pdf.

Croson, R., Schultz, K., Siemsen, E., and Yeo, M. L. (2013). Behavioral operations: the state of the field. Journal of Operations Management, 31(1), pp. 1-5.

Cui, H.T., Raju, J. S., \& Zhang, Z. J. (2007). Fairness and channel coordination. Management Science, 53(8), pp. 1303-1314.

Cui, Y., Chen, L. G., Chen, J., Gavirneni, S., and Wang, Q. (2013). Chinese perspective on newsvendor bias: An exploratory note. Journal of Operations Management, 31(1), pp. 93-97.

D'Urso, D., Di Mauro, C., Chiacchio, F., and Compagno, L. (2017). A behavioural analysis of the newsvendor game: Anchoring and adjustment with and without demand information. Computers and Industrial Engineering, 111, pp. 552-562

Dai, J., and Meng, W. (2015). A risk-averse newsvendor model under marketing-dependency and pricedependency. International Journal of Production Economics, 160, pp. 220-229.

De Véricourt, F., Jain, K., Bearden, J. N., and Filipowicz, A. (2013). Sex, risk and the newsvendor. Journal of Operations Management, 31(1), pp. 86-92.
Demirag, O.C., Chen, Y. F., and Li, J. (2010). Channel coordination under fairness concerns and nonlinear demand. European Journal of Operational Research, 207(3), pp. 1321-1326.

Diehl, E., and Sterman, J. D. (1995). Effects of feedback complexity on dynamic decision making. Organizational Behavior and Human Decision Processes, 62(2), pp. 198-215.

Du, S., Nie, T., Chu, C., and Yu, Y. (2014). Newsvendor model for a dyadic supply chain with Nash bargaining fairness concerns. International Journal of Production Research, 52(17), pp. 5070-5085.

Eeckhoudt, L., Gollier, C., and Schlesinger, H. (1995). The risk-averse (and prudent) newsboy. Management Science, 41(5), pp. 786-794.

Fehr, E., and Gächter, S. (2000). Fairness and retaliation: The economics of reciprocity. The Journal of Economic Perspectives, 14(3), pp. 159-181.

Fehr, E., and Schmidt, K. M. (1999). A theory of fairness, competition, and cooperation. The Quarterly Journal of Economics, 114(3), pp. 817-868.

Feng, T., Keller, L. R., and Zheng, X. (2011). Decision making in the newsvendor problem: A cross-national laboratory study. Omega, 39(1), pp. 41-50.

Fisher, M., and Raman, A. (1996). Reducing the cost of demand uncertainty through accurate response to early sales. Operations Research, 44(1), pp. 87-99.

Gallego, G., and Moon, I. (1993). The distribution free newsboy problem: review and extensions. Journal of the Operational Research Society, pp. 825-834.

Gans, N., and Croson, R. (2008). Introduction to the special issue on behavioral operations. Manufacturing and Service Operations Management, 10(4), pp. 563-565.

Gaur, V., and Seshadri, S. (2005). Hedging inventory risk through market instruments. Manufacturing and Service Operations Management, 7(2), pp. 103-120.

Gavirneni, S., and Isen, A. M. (2010). Anatomy of a newsvendor decision: Observations from a verbal protocol analysis. Production and Operations Management, 19(4), pp. 453-462.

Gavirneni, S., and Robinson, L. W. (2017). Risk aversion and implicit shortage cost explain the Anchoring and Insufficient Adjustment bias in human newsvendors. Operations Research Letters, 45(3), pp. 191-198.

Gavirneni, S., and Xia, Y. (2009). Anchor selection and group dynamics in newsvendor decisions-A note. Decision Analysis, 6(2), pp. 87-97.

Geyskens, I., Steenkamp, J. B. E., and Kumar, N. (1998). Generalizations about trust in marketing channel relationships using meta-analysis. International Journal of Research in Marketing, 15(3), pp. 223-248.

Gino, F., and Pisano, G. (2008). Toward a theory of behavioral operations. Manufacturing and Service Operations Management, 10(4), pp. 676-691.

Herweg, F. (2013). The expectation-based loss-averse newsvendor. Economics Letters, 120(3), pp. 429-432.

Ho, T. H., Su, X., and Wu, Y. (2014). Distributional and Peer-Induced Fairness in Supply Chain Contract Design. Production and Operations Management, 23(2), pp. 161-175. 
Kahneman, D., and Tversky, A. (1979). Prospect theory: An analysis of decision under risk. Econometrica: Journal of the Econometric Society, pp. 263-291.

Kahneman, D., Knetsch, J. L., and Thaler, R. (1986). Fairness as a constraint on profit seeking: Entitlements in the market. The American Economic Review, pp. 728-741.

Kahneman, D., P. Slovic, A. Tversky. (1982). Judgement under uncertainty: Heuristics and biases. Cambridge University Press, New York.

Karlin, S., and Carr, C. R. (1962). Prices and optimal inventory policy. Studies in Applied Probability and Management Science, 4, pp. 159-172.

Katok, E. (2011). Using laboratory experiments to build better operations management models. Foundations and Trends ${ }^{\circledR}$ in Technology, Information and Operations Management, 5(1), pp. 1-86.

Katok, E., Lathrop, A., Tarantino, W., and Xu, S. H. (2001). Jeppesen uses a dynamic-programming-based DSS to manage inventory. Interfaces, 31(6), pp. 54-65.

Katok, E., Olsen, T., and Pavlov, V. (2014). Wholesale pricing under mild and privately known concerns for fairness. Production and Operations Management, 23(2), pp. 285-302.

Keren, B., and Pliskin, J. S. (2006). A benchmark solution for the risk-averse newsvendor problem. European Journal of Operational Research, 174(3), pp. 16431650.

Khouja, M. (1999). The single-period (news-vendor) problem: literature review and suggestions for future research. Omega, 27(5), pp. 537-553.

Köbberling, V., and Wakker, P. P. (2005). An index of loss aversion. Journal of Economic Theory, 122(1), pp. 119131.

Kremer, M., Minner, S., and Van Wassenhove, L. N. (2010). Do random errors explain newsvendor behavior?. Manufacturing and Service Operations Management, 12(4), pp. 673-681.

Kremer, M., Minner, S., and Van Wassenhove, L. N. (2014). On the preference to avoid ex post inventory errors. Production and Operations Management, 23(5), pp. 773-787.

Lau, H. S., and Lau, A. H. L. (1996). The newsstand problem: A capacitated multiple-product single-period inventory problem. European Journal of Operational Research, 94(1), pp. 29-42.

Lau, H. S., and Lau, A. L. (1997). A semi-analytical solution for a newsboy problem with mid-period replenishment. Journal of the Operational Research Society, 48(12), pp. 1245-1259.

Lau, N., and Bearden, J. N. (2013). Newsvendor demand chasing revisited. Management Science, 59(5), pp. 1245-1249.

Lau, N., Hasija, S., and Bearden, J. N. (2014). Newsvendor pull-to-center reconsidered. Decision Support Systems, 58, pp. 68-73.

Li, S. R., Zhang, R. Q., and Fang, W. G. (2017). The newsvendor model with non-zero reference point based on cumulative prospect theory. Computers and Industrial Engineering, 113, pp. 195-205.

Liu, J., Wu, C., and Su, T. (2017). The reference effect newsvendor model customers. Management Decision, 55(5), pp. 1006 1021

Loch, C. H., and Wu, Y. (2007). Behavioral operations management. Foundations and Trends ${ }^{\circledR}$ in Technology, Information and Operations Management, 1(3), pp. 121-232.

Long, X., and Nasiry, J. (2014). Prospect theory explains newsvendor behavior: the role of reference points. Management Science, 61(12), pp. 3009-3012.

Loomes, G., and Sugden, R. (1982). Regret theory: An alternative theory of rational choice under uncertainty. The Economic Journal, 92(368), pp. 805824.

Loomes, G., and Sugden, R. (1987). Testing for regret and disappointment in choice under uncertainty. The Economic Journal, 97, pp. 118-129.

Lurie, N. H., and Swaminathan, J. M. (2009). Is timely information always better? The effect of feedback frequency on decision making. Organizational Behavior and Human Decision Processes, 108(2), pp. 315-329.

Matthews, R. L., and Marzec, P. E. (2012). Social capital, a theory for operations management: a systematic review of the evidence. International Journal of Production Research, 50(24), pp. 7081-7099.

McAfee, R. B., Glassman, M., and Honeycutt, E. D. (2002). The effects of culture and human resource management policies on supply chain management strategy. Journal of Business logistics, 23(1), pp. 1-18.

Meredith, J. (1993). Theory building through conceptual methods. International Journal of Operations and Production Management, 13(5), pp. 3-11.

Mills, E. S. (1959). Uncertainty and price theory. The Quarterly Journal of Economics, 73(1), pp. 116-130.

Moritz, B. B., Hill, A. V., and Donohue, K. L. (2013). Individual differences in the newsvendor problem: Behavior and cognitive reflection. Journal of Operations Management, 31(1), pp. 72-85.

Nagarajan, M., and Shechter, S. (2013). Prospect theory and the newsvendor problem. Management Science, 60(4), pp. 1057-1062.

Ovchinnikov, A., Moritz, B., and Quiroga, B. F. (2015). How to compete against a behavioral newsvendor. Production and Operations Management, 24(11), pp. 1783-1793.

Petruzzi, N. C., and Dada, M. (1999). Pricing and the newsvendor problem: A review with extensions. Operations Research, 47(2), pp. 183-194.

Porteus, E. L. (2002). Foundations of stochastic inventory theory. Stanford University Press.

Prelec, D. (1998). The probability weighting function. Econometrica, pp. 497-527.

Qin, Y., Wang, R., Vakharia, A. J., Chen, Y., and Seref, M. M. (2011). The newsvendor problem: Review and directions for future research. European Journal of Operational Research, 213(2), pp. 361-374.

Rabin, M. (1993). Incorporating fairness into game theory and economics. The American Economic Review, pp. 1281-1302.

Ren, Y., and Croson, R. (2013). Overconfidence in newsvendor orders: An experimental study. Management Science, 59(11), pp. 2502-2517. 
Ren, Y., Croson, D. C., and Croson, R. T. (2017). The overconfident newsvendor. Journal of the Operational Research Society, 68(5), pp. 496-506.

Schweitzer, M. E., and Cachon, G. P. (2000). Decision bias in the newsvendor problem with a known demand distribution: Experimental evidence. Management Science, 46(3), pp. 404-420.

Shore, H. (2004). A general solution for the newsboy model with random order size and possibly a cutoff transaction size. Journal of the Operational Research Society, 55(11), pp. 1218-1228.

Silver, E. A., Pyke, D. F., and Peterson, R. (1998). Inventory Management and Production Planning and Scheduling, 3, New York: Wiley.

Simon, H. A. (1955). A behavioral model of rational choice. The Quarterly Journal of Economics, 69(1), pp. 99-118.

Sterman, J. D. (1989). Modeling managerial behavior: Misperceptions of feedback in a dynamic decision making experiment. Management Science, 35(3), pp. 321-339.

Su, X. (2008). Bounded rationality in newsvendor models. Manufacturing and Service Operations Management, 10(4), pp. 566-589.

Talavera, M. G. V. (2014). Supply Chain Collaboration and Trust in the Philippines. Operations and Supply Chain Management: An International Journal, 7(1), pp. 1-12.

Thorpe, R., Holt, R., Macpherson, A., and Pittaway, L. (2005). Using knowledge within small and mediumsized firms: A systematic review of the evidence. International Journal of Management Reviews, 7(4), pp. 257-281.

Tranfield, D., Denyer, D., and Smart, P. (2003). Towards a methodology for developing evidence-informed management knowledge by means of systematic review. British Journal of Management, 14(3), pp. 207222.
Tversky, A., and Kahneman, D. (1971). Belief in the law of small numbers. Psychological Bulletin, 76(2), p. 105.

Tversky, A., and Kahneman, D. (1992). Advances in prospect theory: Cumulative representation of uncertainty. Journal of Risk and Uncertainty, 5(4), pp. 297-323.

Uppari, B. S., and Hasija, S. (2014). On the consistency between prospect theory and the newsvendor pull-tocenter effect. Working Paper.

Wang, C. X. (2010). The loss-averse newsvendor game. International Journal of Production Economics, 124(2), pp. 448-452.

Wang, C. X., and Webster, S. (2009). The loss-averse newsvendor problem. Omega, 37(1), pp. 93-105.

Wang, C. X., Webster, S., and Suresh, N. C. (2009). Would a risk-averse newsvendor order less at a higher selling price? European Journal of Operational Research, 196(2), pp. 544-553.

Webster, J., and Watson, R. T. (2002). Analyzing the past to prepare for the future: Writing a literature review. MIS Quarterly, pp. 13-23.

Whitin, T. M. (1955). Inventory control and price theory. Management Science, 2(1), pp. 61-68.

Wu, M., Zhu, S. X., and Teunter, R. H. (2014). A risk-averse competitive newsvendor problem under the CVaR criterion. International Journal of Production Economics, 156, pp. 13-23.

Wu, X., and Niederhoff, J. A. (2014). Fairness in selling to the newsvendor. Production and Operations Management, 23(11), pp. 2002-2022.

Zhao, X. B., and Geng, W. (2015). A note on "prospect theory and the newsvendor problem". Journal of the Operations Research Society of China, 3(1), pp. 89-94.

Zhao, Y., Zhao, X., and Shen, Z. J. M. (2016). On learning process of a newsvendor with censored demand information. Journal of the Operational Research Society, 67(9), 0.

\footnotetext{
Abhishek Sharma is a Research Scholar in the area of operations management at Indian Institute of Management, Rohtak, India. His research interests are in the area of behavioral operations and supply chain coordination.

Shirsendu Nandi is an assistant professor in the area of operations in Indian Institute of Management Rohtak. Shirsendu Nandi is FPM (Fellow in Management) from Indian Institute of Management Indore. He also holds Master of Science in mathematics from IIT Kharagpur. He has done his Bachelor of Science with mathematics honours from Presidency college under University of Calcutta. He is the recipient of prestigious N.B.H.M (National Board for Higher Mathematics) Scholarship awarded by Department of Atomic Energy, Govt. of India. He has worked for two years with Wipro Technologies in the area of business intelligence. His teaching interests include subjects like Quantitative Methods, Business Statistics, Advanced Probability and Stochastic Process, Supply Chain Management, Operations Management, Advanced Optimization, Managerial Economics etc. His research interests include Supply chain contracts, Supply chain coordination, Supply chain modelling and network design, Mathematical model building for supply chain and operations related problems.
} 